\title{
Ion Transfer Through DPPC Monolayers
}

\author{
H.A. Santos ${ }^{a}$, C. M. Pereira, ${ }^{*}$ F. Silva \\ Departamento de Química, Faculdade de Ciências do Porto \\ Rua do Campo Alegre, 687, 4169-007 Porto, Portugal. \\ ${ }^{a}$ Present address: Laboratory of Physical Chemistry and Electrochemistry \\ Helsinki University of Technology, PO Box 6100, FIN-02015 HUT, Finland.
}

Received 20 February 2004; accepted in revised form 5 August 2004

\begin{abstract}
The transfer of acetylcholine cation through a monolayer of a lipid, dipalmitoylphosphatidylcholine, formed at a polarized water | 1,2-dichloroethane interface has been studied using electrochemical impedance spectroscopy. The ion transfer process was characterized at different levels of interfacial coverage. From measurement of the cyclic voltammograms and double layer capacitance it was found that cation transfer through dipalmitoylphosphatidylcholine monolayers was cation and phospholipid concentration dependent. An increase on current intensity and capacitance values was observed at more positive potentials due to the transfer of acetylcholine across the interface in the absence or presence of lipid in the organic phase. The thermodynamic and kinetic parameters were also accessed from electrochemical impedance measurements.
\end{abstract}

Keywords: ion transfer, acetylcholine, monolayer, phospholipids, DPPC, impedance spectroscopy.

\section{Introduction}

A lipid monolayer, adsorbed at the interface between two immiscible electrolyte solutions (ITIES), provides a useful model system for studying physicochemical aspects, for example interfacial transport process, on biological and artificial

\footnotetext{
* Corresponding author. E-mail address: cmpereir@fc.up.pt
} 
membranes [1]. A bilayer membrane represents a better model for biological systems, however, the presence of two aqueous | organic interfaces difficult the analysis of the experimental data. The advantage of using a single interface formed at the boundary between two immiscible electrolyte solutions (ITIES) is that the accurate control of the potential drop across the monolayer adsorbed is easily achieved and can be controlled precisely [2], thus allowing its effect on ion transfer [3-8] and electron transfer $[9,10]$ kinetics to be determined. Thus, electrochemical techniques, such as impedance spectroscopy, can be used both to characterise the monolayer and to study interfacial processes $[3,11]$.

There are several studies in the literature concerning the adsorption of phospholipids at the ITIES, but most of them are at water $\mid$ nitrobenzene (w $\mid$ NB) systems $[1,2,3,5,12-16]$ and only a few at water | 1,2-dichloroethane (w | DCE) systems $[4,6,17]$. The later system shows properties that favour the formation of a more condensed monolayer structure of the adsorbed lipid, in contrast with what occurs at the nitrobenzene/water interface where the nitrobenzene molecules penetrate into the hydrophobic part of the lipid monolayer, and thus prevents the formation of a condensed monolayer [5,13,14]. A further advantage of using DCE instead of NB solvent is that a larger and more useful potential window [18] can be achieved.

It is not easy to reconcile the large ensemble of data obtained from the studies of ion transfer $[2,6,13,18]$ across lipid monolayers since most of them have been obtained on different types of monolayers.

Some results have shown a blocking effect, to ion transfer, of the adsorbed lipid layer [19] while other studies point out to a retardation effect $[3,4]$ due to the size of the transferring ion and to the state of the monolayer [16]. More recent studies indicate that there is no retardation $[20,21]$ or enhancement $[5,6,22,23]$ of ion transfer across phospholipid monolayers at ITIES.

These conflicting observations indicate that the present understanding of the structure of the layers at electrified interfaces is far from being conclusive especially on what the transfer of ions through the phospholipid layers is considered. The role played by the interfacial potential drop and the degree of 
dissociation of lipid polar headgroups seems to be of major importance to define the film permeability to ionic species.

The present work aims to characterize electrochemically the ion transfer of acetylcholine $\left(\mathrm{Ach}^{+}\right)$cation across a dipalmitoylphosphatidylcholine (DPPC) layer formed at 1,2-dichloroethane | water interface. Cyclic voltammetry (CV) and electrochemical impedance spectroscopy (EIS) were used to extract the information on the voltammograms and interfacial capacitance, and thus to characterize the cation transfer at the polarized interface. The $\mathrm{Ach}^{+}$transfer through DPPC monolayers was also characterized at different levels of interface coverage and the thermodynamic and kinetic parameters were also achieved using electrochemical impedance. The data obtained will be discussed against the current knowledge on the structure and stability of phospholipid monolayer at liquid | liquid interfaces described before.

\section{Experimental}

\section{Chemicals}

The electrochemical measurements have been done using the organic solvent 1,2dichloroethane (1,2-DCE, Aldrich, 99\%). Dipalmitoylphosphatilcholine (DPPC, Sigma, $>99 \%$ ), used without further purification. The lipid stock solution was prepared in chloroform (Pronolab, p.a.). To prepare the different phospholipid solutions the required amount of phospholipid solution in chloroform was added to a known volume of the organic phase.

All aqueous solutions were prepared using fresh Millipore, Milli-Q water (18 $\left.\mathrm{M} \Omega . \mathrm{cm}^{-1}\right)$. The aqueous base electrolyte was sodium chloride ( $\mathrm{NaCl}$, Merck, p.a.) and sodium tetraphenylborate (NaTPB, Aldrich, $>99.5 \%$ ). The organic base electrolyte tetraoctylammonium tetraphenylborate (TOATPB) was obtained by precipitation from sodium tetraphenylborate and bromide tetraoctylammonium (TOABr, Fulka, > 98\%). Lithium chloride (LiCl, Merck, p.a.), sodium hydrogen phosphate $\left(\mathrm{Na}_{2} \mathrm{HPO}_{4}\right.$, Merck, p.a.) and sodium dihydrogen phosphate dihydrate $\left(\mathrm{NaH}_{2} \mathrm{PO}_{4} \cdot \mathrm{H}_{2} \mathrm{O}, \mathrm{M} \& \mathrm{~B}\right)$ were used as aqueous phase solutions. Acetylcholine 
chloride was purchased from Aldrich ( $>99.5 \%$ ). All chemicals were used as received. All experiments were carried out at room temperature and at $\mathrm{pH} \sim 7$.

\section{Electrochemical measurements}

Electrochemical impedance and cyclic voltammetry measurements were carried out using a Solartron 1250 frequency response analyzer with potential control by a Solartron 1287 potentiostat (Solartron, UK). The measurements were carried out using a sinusoidal potential signal with amplitude of $20 \mathrm{mV}$. The potentials were measured at range frequencies from $200 \mathrm{~Hz}$ to $0.5 \mathrm{~Hz}$, with 15 points per decade. The reference electrodes used for the four electrode capacitance measurements were $\mathrm{Ag} / \mathrm{AgCl}$ and the counter electrodes were Pt coils. The area of the liquid-liquid interface was $0.28 \mathrm{~cm}^{2}$. The cell interface is positioned between two Luggin capillaries to achieve minimization of the $I R$ drop. All electrochemical experiments were carried out inside a Faraday cage to improve noise reduction.

The electrochemical cell used in the current study can be represented by:

Cell 1:

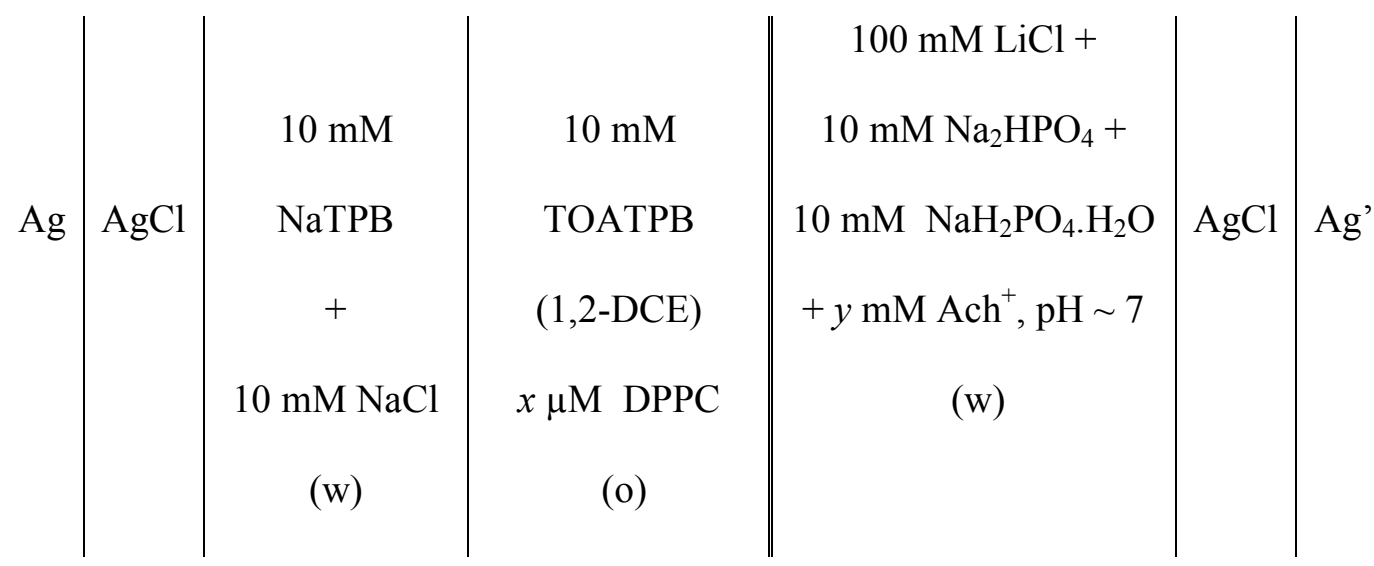

Before the impedance measurements a cyclic voltammogram was registered, using a scan rate of $50 \mathrm{mV} / \mathrm{s}$, to evaluate the potential window. 
In the present work it was decided not to use the $\mathrm{Ach}^{+}$ion in the organic phase in order to prevent any interaction between the cation and the phospholipid in the bulk of the organic phase.

The transfer of $\mathrm{Ach}^{+}$through DPPC films at 1,2-DCE | water interface was studied after the addition of a required amount of $\mathrm{Ach}^{+}$at the aqueous phase. Upon the addition of the species to the cell, the system was left in equilibrium ca. 60 minutes before beginning the impedance measurements. Each potential measure was done only 30 seconds after the applied potential in the cell system. The impedance spectrum scan was done from the higher to the lower frequencies range. All the impedance data were collected using a software developed by Pereira [24] and the results were fitted using the equivalent circuit shown in Fig. 1 using the EQUIVCRT module present in Autolab software and developed by Boukamp [25]. Fitting errors were always less than $5 \%$.

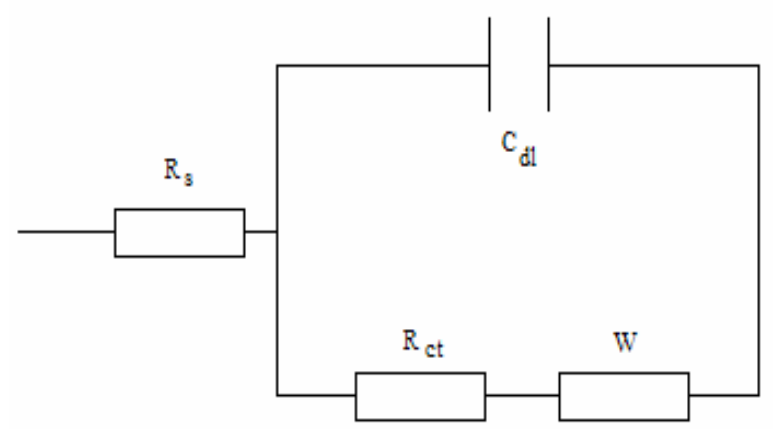

Figure 1. Equivalent electrical circuit: $R_{s}=$ solution resistance; $C_{d l}=$ double layer capacitance; $\mathrm{W}=$ Warburg impedance; $\mathrm{R}_{\mathrm{ct}}=$ charge transfer resistance.

The cell potential $E$ was corrected in order to evaluate the Galvani potential difference across the interface using a procedure described in the literature [26] using $\mathrm{TEA}^{+}$ion as internal standard $\left(\Delta \phi_{\mathrm{w} \rightarrow 1,2-\mathrm{dce}}^{0^{\prime}}=19 \mathrm{mV}[27]\right)$.

\section{Results and discussion}

\section{Cyclic voltammetry}

Fig. 2 illustrates the voltammetric behaviour of the transfer of acetylcholine cation at the 1,2-DCE | water interface. The increase in current observed at the edges of the potential window are due to the transfer of $\mathrm{TOA}^{+}$ 
(tetraoctylammonium) and $\mathrm{TPB}^{-}$(tetraphenylborate) ion from dichloroethane to water, respectively [28]. In the presence of $\mathrm{Ach}^{+}$in the aqueous phase a voltammetric wave is observed within the potential window which corresponds to the transfer of $\mathrm{Ach}^{+}$and the half-wave potential can be correlated with the transfer potential of $\mathrm{Ach}^{+}$ion.

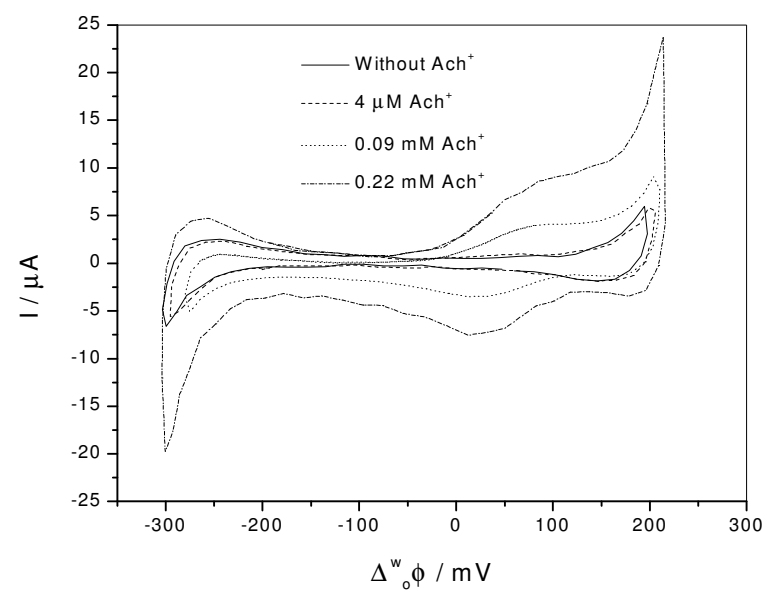

Figure 2. Cyclic voltammograms obtained at the 1,2-DCE | water interface, when different concentrations of $\mathrm{Ach}^{+}$ion were added at the aqueous phase: $0,4 \mu \mathrm{M}, 0.09$ and $0.22 \mathrm{mM}$. Conditions: supporting electrolyte; $10 \mathrm{mM}$ TOATPB, in organic and 100 $\mathrm{mM} \mathrm{LiCl}, 10 \mathrm{mM} \mathrm{Na} 2 \mathrm{HPO}_{4}$ and $10 \mathrm{mM} \mathrm{NaH}_{2} \mathrm{PO}_{4} \cdot \mathrm{H}_{2} \mathrm{O}$ in aqueous phase; scan rate: 50 $\mathrm{mV} / \mathrm{s} ; \mathrm{pH} \sim 7$.

The adsorption of phospholipid is concentration and potential dependent; therefore, to assess the effect of lipid films on the transfer of $\mathrm{Ach}^{+}$two different degrees of coverage were used: $1.4 \mu \mathrm{M}$ and $30 \mu \mathrm{M}$ DPPC. For the lower lipid concentration the surface is not completely covered and for the higher concentration the saturation of the adsorbed layer is reached.

In the presence of adsorbed phospholipid, a decrease in peak current due to the transfer of $\mathrm{Ach}^{+}$is observed. This can be verified analysing the calibration curves in Fig. 3. From the plot in Fig. 3 a decrease of $16 \%$ and $59 \%$ in the slope is observed when we go from the situation of absence of phospholipid to, respectively, a solution of $1.4 \mu \mathrm{M}$ and $30 \mu \mathrm{M}$ of DPPC in the organic phase. From the slope of the plot in Fig. 3, in the absence of lipid, it is possible to 
estimate a value of $5.4 \times 10^{-6}$ for the diffusion coefficient of acetylcholine ion in the aqueous phase.

The differences observed can be explained if we consider the formation of a stable DPPC layer at the interface which could reduce the effective interfacial area.

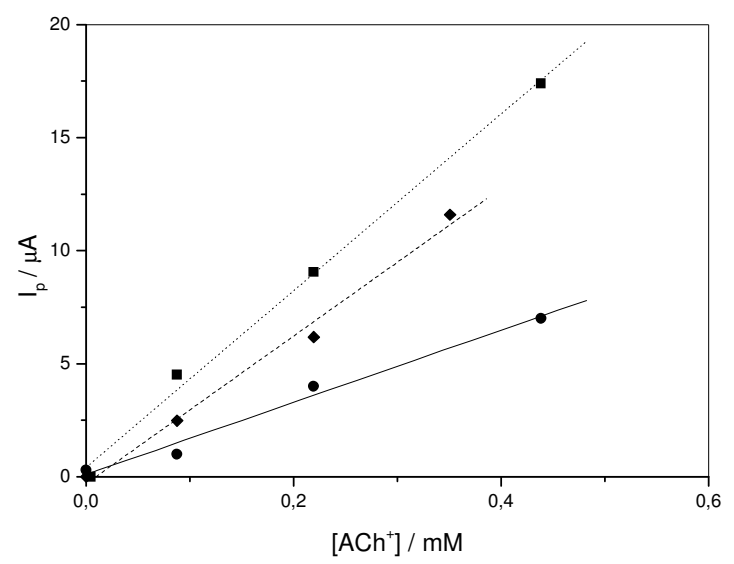

Figure 3. Plot of peak current as a function of acetylcholine concentration in the absence $(\boldsymbol{\square})$ and in the presence of $1.4 \mu \mathrm{M}(\bullet)$ and $30 \mu \mathrm{M}(\bullet)$ of DPPC in the organic phase.

\section{Capacitance studies}

The previous results observed by the voltammetric measurements were corroborated by double layer capacitance $\left(\mathrm{C}_{\mathrm{dl}}\right)$ studies. As shown before, the electric equivalent circuit shown in Fig. 1 can represent the interface. Provided that the transfer of acetylcholine cation in the solution is controlled by linear and semi-infinite diffusion and a first-order rate law governs its transfer across the ITIES, the faradaic impedance $\mathrm{Z}_{\mathrm{f}}$ can be written as [29]:

$$
\mathrm{Z}_{\mathrm{f}}=\mathrm{R}_{\mathrm{ct}}+\mathrm{Z}_{\mathrm{w}}
$$

The charge transfer resistance is given by:

$$
\mathrm{R}_{\mathrm{ct}}=\frac{\mathrm{RT}}{(\mathrm{zF})^{2} A \mathrm{~K}^{w \rightarrow o}\left(C^{0, w}\right)^{1-\alpha}\left(C^{0, o}\right)^{\alpha}}
$$


where $\mathrm{K}^{\mathrm{w} \rightarrow \mathrm{o}}$ is the first-order rate constant of the acetylcholine ion transfer from the aqueous to the organic phase, $\mathrm{z}$ is the charge of the acetylcholine ion and the other symbols have the classical definitions. Under the reasonable assumption of $\alpha=0.5$ and measuring $R_{c t}$ at the equilibrium potential this relationship can be simplified to:

$$
\mathrm{R}_{\mathrm{ct}}=\frac{\mathrm{RT}}{\mathrm{F}^{2} A \mathrm{~K}_{\mathrm{ap}}^{\mathrm{w} \rightarrow 0} C^{0, w}}
$$

where $\mathrm{K}_{\mathrm{ap}}^{\mathrm{w} \rightarrow \mathrm{o}}$ is an apparent first-order rate constant of the acetylcholine ion transfer from the aqueous to the organic phase.

Hence, the electrochemical impedance method was employed to obtain the kinetic parameters of acetylcholine ion across phospholipid monolayers at 1,2DCE | water interface using cell 1.

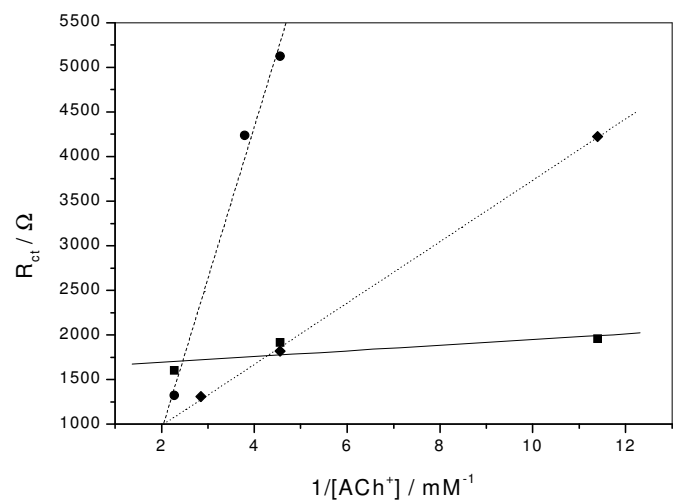

Figure 4. Plot of the charge transfer resistance $v s$. the inverse of acetylcholine concentration in the absence $(\square)$ and in the presence of $1.4 \mu \mathrm{M}(\bullet)$ and $30 \mu \mathrm{M}(\bullet)$ of DPPC in the organic phase.

Fig. 4 shows a plot of the charge transfer resistance as a function of the inverse of acetylcholine concentration. A linear plot is found as described by equation 3 from the slope of which rate constant for the transfer of acetylcholine ions can be calculated. The results are summarized in table 1 . The rate constant for the transfer of the acetylcholine ion from aqueous to organic phase in the absence of phospholipid monolayer is $3.0 \times 10^{-2} \mathrm{~cm}^{-1}$. This value is of the same order of magnitude of that obtained by Shao and Girault [30] using chronocoulometry $\left(\mathrm{K}^{0}\right.$ 
$=3.0 \times 10^{-2} \mathrm{~cm}^{-1}$ ) although the results obtained in this work could be subjected to a greater experimental error as a consequence of a possible oversimplification of equation 3.

Table 1. Apparent rate constant values for the transfer of acetylcholine cation across a DPPC monolayer.

\begin{tabular}{|c||c||c||}
\hline System & $\mathrm{K}_{\mathrm{ap}}^{\mathrm{w} \rightarrow \mathrm{o}} / \mathrm{cm}^{-1}$ & $\mathrm{R}$ \\
\hline \hline absence of lipid layer & $3.0 \times 10^{-2}$ & 0.984 \\
\hline \hline $1.4 \mu \mathrm{M}$ DPPC & $2.8 \times 10^{-3}$ & 0.999 \\
\hline \hline $30 \mu \mathrm{M}$ DPPC & $5.6 \times 10^{-4}$ & 0.994 \\
\hline
\end{tabular}

When the concentration of DPPC is varied from $1.4 \mu \mathrm{M}$ to $30 \mu \mathrm{M}$ the rate constant for the acetylcholine transfer $\left(\mathrm{K}_{\mathrm{ap}}^{\mathrm{w} \rightarrow \mathrm{o}}\right)$ goes from $2.8 \times 10^{-3} \mathrm{~cm}^{-1}$ to $5.6 \times$ $10^{-4} \mathrm{~cm}^{-1}$ showing a significant decrease in the apparent rate of ion transfer. This decrease cannot be explained solely by a change in the active interfacial area and must be a result of the formation of a stable phospholipid monolayer at the interface. Such monolayer should block the interface and the ion transfer is retarded as the phospholipid concentration in the organic phase increases.

From the fitting of the impedance data to the equivalent circuit of Fig. 1 the value of the interfacial capacity is obtained and is plotted in Fig. 5. The data display the effect of the applied potential and concentration of $\mathrm{Ach}^{+}$in the aqueous phase. The results in Fig. 5 show that there is no change on the adsorption process at more negative potentials when acetylcholine ion was added to the aqueous phase. However, at more positive potentials there is an increase in the capacitance values with a higher value at about $125 \mathrm{mV}$ corresponding to the potential of transfer of $\mathrm{Ach}^{+}$from the aqueous to the organic phase. This increase in 
capacitance is probably due to the transfer of charged species through the interface.

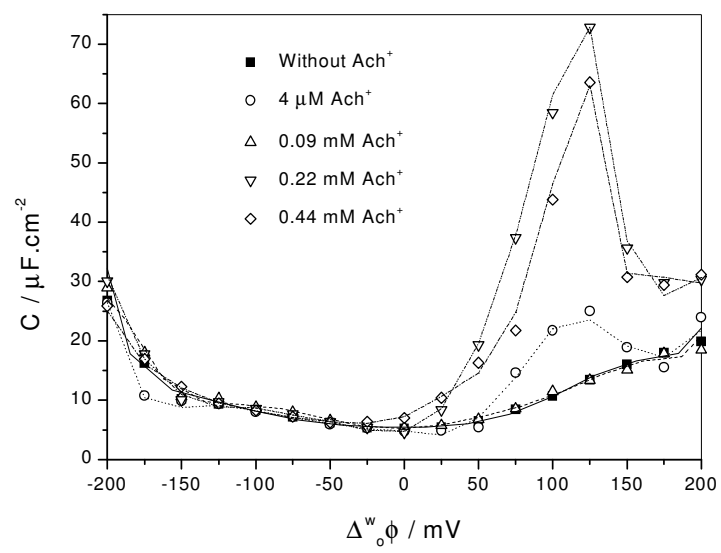

Figure 5. Double layer capacitance as a function of applied potential at the 1,2-DCE | water interface in the presence of different concentration values of $\mathrm{Ach}^{+}$added to the aqueous phase: $0,4 \mu \mathrm{M}, 0.09,0.22$ and $0.44 \mathrm{mM}$. The lines are only a guide to the eye.

These results are in agreement with those obtained using cyclic voltammetry (ion transfer of $\mathrm{Ach}^{+}$ion ca. $116 \mathrm{mV}$ ). It is also possible to observe that as the concentration of acetylcholine ion increases in the aqueous phase the capacitance values also increase, due to the ion transfer of $\mathrm{Ach}^{+}$across the interface.

\section{Conclusions}

The use of ion transfer through ITIES proved to be an interesting method for the evaluation of interaction of ions with phospholipids and valuable information can be extracted by this method.

The transfer of acetylcholine cation shows an increase in peak current with the increase in concentration. The presence of the acetylcholine cation in the aqueous phase has no effect in the adsorption process of the phospholipid at the interface. The ion transfer of acetylcholine cation through DPPC monolayers at different levels of phospholipid coverage seems to have a strong concentration dependence, which could be the result of a strong interaction between the acetylcholine ion and the phospholipids film.

The ion transfer process was found to be dependent on packing density of the monolayer, surface charge density, and charge and size of transferring ions. 


\section{Acknowledgements}

The authors would like to thank FCT for financial support (CIQ L4 and FEDER for the project POCTI/QUI/42472/2001).

\section{References}

1. T. Kakiuchi, M. Nakanishi, M. Senda, Bull. Chem. Soc. Jpn. 62 (1989) 403.

2. T. Kalkiuchi, T. Kondon, M. Kotani, M. Senda, Langmuir 8 (1992) 169.

3. J. Koryta, L.Q. Hung, A. Hofmanova, Studia Biophys. 90 (1982) 25.

4. V.J. Cunnane, D.J. Schiffrin, M. Fleischmann, G. Geblewicz, D.E. Williams, J. Electroanal. Chem. 243 (1988) 455.

5. T. Kakiuchi, M. Kotani, J. Nagouchi, M. Nakanishi, M. Senda, J. Colloid Interface Sci. 149 (1992) 279.

6. A.-K. Kontturi, K. Kontturi, L. Murtomäki, B. Quinn, V.J. Cunnane, J. Electroanal. Chem. 424 (1997) 69.

7. S.G. Chesniuk, S.A. Dassie, L.M. Yudi, A.M. Baruzzi, Electrochim. Acta 43 (1998) 2175.

8. D. Grandell, L. Murtomäki, C. Sundholm, J. Electroanal. Chem. 469 (1999) 72.

9. Y. Cheng, D.J. Schiffrin, J. Chem. Soc., Faraday Trans. 90 (1994) 2517.

10. M. Tsionsky, A.J. Bard, M.V. Mirkin, J. Am. Chem. Soc. 119 (1997) 10785.

11. A.G. Volkov, D.W. Deamer (Eds), Liquid | Liquid Interface; Theory and Methods, CRC Press, Boca Raton, Florida, 1996.

12. T. Wandlowski, S. Racinsky, V. Marecek, Z. Samec, J. Electroanal. Chem. 22 (1987) 281.

13. T. Wandlowski, V. Marecek, Z. Samec, J. Electroanal. Chem. 242 (1988) 277.

14. T. Kakiuchi, M. Yamane, T. Osakai, M. Senda, Bull. Chem. Soc. Jpn. 60 (1987) 4223.

15. T. Kakiuchi, M. Nakanishi, M. Senda, Bull. Chem. Soc. Jpn. 61 (1988) 1845.

16. T. Kakiuchi, T. Kondo, M. Senda, Bull. Chem. Soc. Jpn. 63 (1990) 3270. 
17. H.H. Girault, D.J. Schiffrin, J. Electroanal. Chem. 179 (1984) 277.

18. J. Koryta, Electrochim. Acta 24 (1979) 293.

19. C.J. Slevin, S. Ryley, D.J. Walton, P.R. Unwin, Langmuir 14 (1998) 5331.

20. R.M. Allen, D.E. Williams, Faraday Discuss. 104 (1996) 281.

21. D. Grandell, L. Murtomäki, K. Kontturi, G. Sundholm, J. Electroanal. Chem. 463 (1999) 242.

22. S.G. Chesniuk, S.A. Dassie, L.M. Yudi, A.M. Baruzzi, Electrochim. Acta 43 (1998) 2175.

23. S.G. Chesniuk, S.A. Dassie, L.M. Yudi, A.M. Baruzzi, Langmuir 14 (1998) 5226.

24. C.M. Pereira, Ph.D. Thesis, "Desenvolvimento de sensores voltamétricos com base em microinterfaces líquido-líquido suportadas em membranas", Porto, Portugal, 1997.

25. B.A. Boukamp, J. Electrochem. Soc. 142 (1995) 1885.

26. M.H.M. Caçote, C.M. Pereira, L. Tomaszewski, H.H. Girault, F. Silva, Electrochim. Acta 49 (2004) 263.

27. T. Wandlowski, V. Mareček, Z. Samec, Electrochim. Acta 35 (1990) 1173-1175.

28. Z. Samec, V. Mareček, J. Weber, J. Electroanal. Chem. 100 (1979) 841.

29. M. Sluyters-Rehbach, J.H. Sluyters, in E. Yeager and S. Sarangapani (Eds.), Comprehensive Treatise of Electrochemistry, Vol. 9, Plenum Press, New York and London, 1984, pp. 177-292.

30. Y. Shao, H.H. Girault, J. Electroanal. Chem. 282 (1990) 59. 